\title{
Community Resilience during the COVID 19 Pandemic: Experiences of Community-Based Violence Prevention and Recidivism Reduction Program Administrators
}

\author{
Megan Alderden ${ }^{1} \cdot$ Xavier Perez $^{1}$ \\ Received: 28 May 2021 / Accepted: 29 September 2021 / \\ Published online: 3 November 2021 \\ (c) Southern Criminal Justice Association 2021
}

\begin{abstract}
Community-based agencies play a notable role in local violence prevention and reentry services in the United States. The COVID-19 pandemic and governmental responses to contain its spread fundamentally transformed the day-to-day lives of most individuals and the workplace. This study examined the challenges experienced and adaptations employed by community-based organizations as they navigated shelter-in-place orders and other workplace and community restrictions. Between July and September of 2020, researchers completed 16 semi-structured interviews with agency administrators of community-based organizations serving at-risk youth or formerly incarcerated persons operating in a large Midwestern city. The findings highlight several challenges faced by agency administrators as they attempted to maintain services to their clients, including having to move from largely in-person service modalities to methods of contact and communication that embraced social distancing and virtual interaction. They also actively responded to the health safety needs of their staff, clients, and community by instituting new safety protocols, like staff and client COVID-19 testing, handing out personal protection equipment and supplies, and educating community members. The findings demonstrate a high degree of community mobilization and resilience in light of a global crisis.
\end{abstract}

Keywords COVID-19 $\cdot$ Pandemic $\cdot$ Crime prevention $\cdot$ Community resilience

\section{Introduction}

2020 represented a significant, unprecedented challenge for society generally, but particularly for criminal justice and social service agencies as they navigated the pandemic and other unexpected events, including civil unrest and increased

\footnotetext{
Megan Alderden

megan.alderden@depaul.edu

1 DePaul University, Chicago, IL, USA
} 
neighborhood violence. The novel coronavirus (COVID-19) pandemic transformed the social landscape for criminal justice agencies, social service providers and the populations they serve. The first confirmed case of COVID-19 in the United States occurred in January 2020, and by mid-March most states and local jurisdictions began to issue "shelter-in-place" or "stay-at-home" orders that required most agencies to shutter in-person operations and work remotely. These "shelter in place" or "stay-at-home" orders generally extended through the end of May, and continued to some extent through early 2021, including continued restrictions on public and indoor gatherings.

During the early days of the pandemic, national news outlets reported a reduction in police calls for service or 911 calls (Jackman, 2020; Waldrop, 2020). For example, following the shelter-in-place orders, Shayegh and Malpede (2020) documented a 43\% decline in crime in San Francisco and 50\% decline in Oakland. Furthermore, Pietrawska et al. (2020) identified a 35\% decline in Chicago crime five weeks after the governor issued the orders. On the other hand, Ashby's (2020) research showed no consistent pattern of change during the pandemic. Changes in crime appeared to be random and dependent on the city or county under examination. Other research suggests that shelter in place orders did not influence Chicago homicides and may have actually contributed to a $15 \%$ increase in Philadelphia homicides (Philadelphia Police, 2020).

Researchers posited that the noticeable reductions in crime resulted from lifestyle and group behavior changes. The shelter-in-place orders disrupted daily routines requiring individuals to remain home and limit the opportunities and places for offenders and victims to converge (Stickle \& Felson, 2020). Pietrawska et al (2020) reported sharp declines in particular crimes in public places like stores, restaurants, and entertainment areas, while crimes taking place in private residences largely remained consistent (Campbdelli et al., 2020; Payne \& Morgan, 2020; Shayegh \& Malpede, 2020). Boman and Gallupe (2020) argue that disruptions to established social patterns explain the reduction in crime. Specifically, shelter-in-place orders and social distancing requirements limit peer interactions and the context for group behavior activity, likely impacting minor crimes committed by groups of peers appear to be in decline.

Concurrently, however, crimes committed by sole perpetrators such as intimate partner violence (IPV), serious battery, and homicide remained consistent or in some instances increased (Boman \& Gallupe, 2020). Many urban communities experienced significant increases in violent crime and civil unrest. In the first 10 months of 2020, violent crimes increased dramatically; homicide rates increased $29 \%$, aggravated assaults increased $10 \%$, and gun assaults increased $10 \%$ when comparing January to October 2020 to the same time period in 2019 (Rosenfeld \& Lopez, 2020). Although the exact causes of the increase in violent crime are still unknown (Rosenfeld \& Lopez, 2020), some speculated that factors such as changes in policing, civil unrest, and community-based service disruptions were partially to blame (Singal, 2021).

At the same time, correctional officials were trying to manage the introduction and spread of COVID-19 within their institutions. As of 2019, there were nearly 2.2 million people incarcerated in local jails and state and federal prisons in the 
United States (Carson, 2020; Zeng \& Minton, 2021). Mass incarceration because of decades-long policies that encouraged the use of jail and prison and instituted lengthy sentences meant that many correctional facilities were managing the spread of a highly infectious respiratory disease in historically overcrowded and sometimes aging facilities that are difficult to sanitize effectively (Franco-Paredes et al., 2020). Moreover, many imprisoned individuals have chronic health conditions that increase the risk associated with COVID-19 infections and deaths, and many correctional facilities lack adequate health care service to address the needs of those who do get sick (Hawks et al., 2020). As of June 2020, the infection rate for state and federal prisoners $(3,251$ per 100,000 prisoners) was 5.5 times that of the general population (587 per 100,000 population) (Saloner et al., 2020).

In response to the high rates of COVID-19 among those incarcerated, civil rights lawyers and advocates argued, and sometimes sued for, early release of individuals, and many prison administrators also worked to decrease the number of persons living in correctional facilities (Sherry, 2021). This may have inadvertently enabled the spread of COVID-19 into already vulnerable communities. One study examining arrests and releases in Cook County, IL found that individuals cycling in and out of the Cook County Jail, one of the largest jail facilities in the U.S., accounted for $15.9 \%$ of all COVID-19 cases in Chicago alone during the early months of the pandemic. Neighborhood arrest and jail release rates explained 55\% of the variation in COVID-19 infections by zip code in Cook County even after controlling for other factors, such as poverty and population density, leading the study's authors to conclude that the historic overuse of arrest and incarceration in poor, minority communities makes these communities vulnerable to future pandemics (Reinhart \& Chen, 2020). In a study of urban areas in the U.S., Adhikari and colleagues (2020) found that counties with lower reported median income and high percentages of nonWhite residents, characteristics that are also associated with higher violent crime and incarceration rates, had COVID-19 infection rates that were 8 times higher and death rates that were 9 times greater than similarly situated majority White communities. African Americans had the highest rate of COVID-19-related deaths across age groups (Ford et al., 2020), although Latinx populations and Native Americans also had considerable higher rates of mortality in comparison to Whites (Burki, 2021; Podewils et al., 2020).

In all, the implications of the pandemic on crime and justice in the US is still unknown. The scant research that currently exists on its affect suggests at minimum the pandemic may have resulted in decreases in certain types of crime, but not all. Moreover, the pandemic required criminal justice agencies to shift operations in an attempt to prevent the spread of COVID-19. Miller and Blumstein (2020) argue a national research agenda on the effect of COVID-19 pandemic on crime, victimization and the system's response is needed to fully appreciate its significance and to develop effective policies moving forward. This includes considering how social distancing and other mitigation strategies were associated with crime changes and whether and how returning to normal activities similarly effects crime rates. As part of this agenda, criminologist must also consider the role of community resiliency in mitigating the effect of large-scale events and the role of community-based agencies in public safety. 


\section{Community Resiliency}

What makes communities resilient to external shocks, such as pandemics, is important to understand given the high probability of future large-scale events (World Health Organization, 2021). Norris et al. (2008) define community resilience as "a process linking a set of networked adaptive capacities to a positive trajectory of functioning and adaptation in constituent populations after a disturbance." Community resilience is understood generally as a community's ability to utilize available resources to respond and recover from crises and traumatic events. In their conceptualization of community resilience, Norris et al. (2008) advanced four network adaptive capacities: information and communication, community competence, social capital, and economic development. Pfefferbaum and Klomp (2013) argue that community resilience emerges from collective efforts to join the goal of fostering a response for recovery. In working class communities, social capital mitigates the challenges of adverse circumstances and activates social networks. Social capital as actual or potential resources linked to one's social networks (Kawachi \& Berkman, 2000). The presence of social capital coupled with community resilience therefore assists community develop adaptive strategies against potential threats or crises.

Community-based agencies are an integral part of the strategy to help communities address and recover from extreme and traumatic incidents, as they are one avenue by which individuals receive social support, an important catalyst of community resilience following adverse events (Norris et al., 2008). In many urban neighborhoods, community-based agencies are the primary organizations that support violence prevention and intervention efforts and assist those returning from incarceration. The utilization of community-based agencies to achieve violence prevention and recidivism reduction goals is purposeful; it has long been realized that community-led programs experience greater acceptance within neighborhoods, particularly where residents are suspicious and less trusting of government-led efforts (Mercy et al., 1993). The desire to include communities in the design and implementation of violence prevention and intervention programs and reentry support has resulted in significant funding aimed at capacity building, technical assistance, and community mobilization and empowerment to increase the number and diversity of evidence-based practices and programs within high crime communities (Vivolo et al., 2011). Thus, it is important to document and understand how community-based agencies adapted to the pandemic given their relative importance not only in providing services to vulnerable populations (i.e., at-risk youth and previously incarcerated persons), but in overall community health. This study sought to document how community-based agencies responded to the everchanging environment during the COVID-19 pandemic.

\section{Method}

\section{Sample}

The interview data analyzed for this article were originally part of a larger evaluation of the grant-making process used by a governmental agency that serves a large 
urban county in the Midwest. The original sample included 20 community-based, non-profit agencies that had recently sought or received government funding to support violence prevention, recidivism reduction, or restorative justice programming.

The government agency provided researchers with a list of organizations that included at least one agency contact person, typically the agency director. The researchers then sent emails inviting the agency director or other agency representative to participate in an interview. Agency administrators who preferred to have more than one person complete an interview were given that option. Those who agreed to participate in an interview signed an Institutional Review Board approved informed consent form prior to the interview.

Theevaluation teaminterviewed 16 individuals representing 15 differentcommunitybased agencies, for an overall response rate of $75 \%$. One site requested interviews with two different individuals. This additional interview was included in the analysis as each individual interviewed spoke to different aspects of how their organization navigated program operations and implementation during the pandemic. Table 1 provides a summary of the characteristics of the agencies with completed interviews. Of those agency staff interviewed, $40 \%$ worked in agencies who received funding for violence prevention services, $33 \%$ for restorative justice programs, and $27 \%$ for services that aim to reduce recidivism. The majority of agencies focused on younger individuals, with $80 \%$ serving the emerging adult population (18 to 24 years) and $87 \%$ serving adolescents (17 years and younger). These agencies provided a wide range of services, including general support services (defined as services that assist with housing, food, job placement, referrals to substance use treatment) and case management (33\%); therapeutic services and counseling (33\%); job training and workforce development (27\%); conflict mediation, peace circles and other restorative justice programming (27\%); and civic engagement and youth leadership programming (20\%). Beyond governmental grants, most of the individuals interviewed worked at agencies that relied on a variety of funding sources to support their activities, the most common, outside of governmental grants, being private foundations (67\%) and individual and corporate donors (67\%).

\section{Procedure}

A semi-structured interview guide was used; it contained questions asking participants to share information about their organizations and the communities they serve, decisions associated with the grant making process (application development, etc.), program implementation, and program sustainability (see Appendix A). The interview guide also contained questions related to implementing and sustaining program activities during the COVID-19 pandemic. Emergency stay-at-home orders had just begun to take effect in the United States when the researchers began developing the interview guide. As such, the short- and long-term challenges programs would face as they navigated this uncharted reality were unknown. The research team felt the interviews offered a unique opportunity to gain feedback from community agency administrators on how the pandemic affected their operations and how their agencies adapted. 
Table 1 Characteristics of Agencies $(\mathrm{N}=15)$

\begin{tabular}{|c|c|c|}
\hline Characteristic & Frequency & Percent \\
\hline \multicolumn{3}{|l|}{ Grant Type } \\
\hline Recidivism Reduction $(\mathrm{N}=6)$ & 4 & $27 \%$ \\
\hline Restorative Justice $(\mathrm{N}=6)$ & 5 & $33 \%$ \\
\hline Violence Prevention $(\mathrm{N}=8)$ & 6 & $40 \%$ \\
\hline \multicolumn{3}{|l|}{ Target Population } \\
\hline 17 years and younger (Adolescents) & 13 & $87 \%$ \\
\hline 18 to 24 years (Emerging Adults) & 12 & $80 \%$ \\
\hline 25 years and older (Adults) & 3 & $20 \%$ \\
\hline \multicolumn{3}{|l|}{ Types of Services } \\
\hline Support services/Case management & 5 & $33 \%$ \\
\hline Job training/Workforce Development & 4 & $27 \%$ \\
\hline Therapeutic services; Counseling & 5 & $33 \%$ \\
\hline Civic engagement/Youth Leadership & 3 & $20 \%$ \\
\hline Mediation/Peace circles/Other RJ & 4 & $27 \%$ \\
\hline $\begin{array}{l}\text { Other (Legal services, education/life skills development, } \\
\text { community forums) }\end{array}$ & 6 & $40 \%$ \\
\hline \multicolumn{3}{|l|}{ Funding Sources } \\
\hline Governmental grants (Federal, County, Municipal) & 15 & $100 \%$ \\
\hline Private foundations & 10 & $67 \%$ \\
\hline Individual and corporate donors & 10 & $67 \%$ \\
\hline Fee for service & 3 & $20 \%$ \\
\hline
\end{tabular}

Some percentages will not equal $100 \%$ as many agencies served multiple target populations, provided more than one type of service, or reported more than one type of funding source

The research team conducted the interviews between July and September of 2020. The interviews took one to two hours to complete. One interviewer, accompanied by a note taker, conducted each interview using video conferencing software. The interviewers and note takers took detailed notes during the interviews and attempted to record information verbatim. The research team then coded the interviews for major themes and associated sub-themes.

\section{Analysis}

As noted, the research team collected the data as part of an evaluation of the grantmaking process used by a governmental agency to fund programming aimed at violence prevention, recidivism reduction, and restorative justice practices. The findings presented here are coding of responses to the interview questions specific to the impact of COVID-19 pandemic on agency operations as well as any passages in which the terms "COVID" or "pandemic" were present.

The research team coded the interview data using the Iterative Thematic Inquiry (ITI) method (see Morgan \& Nica, 2020 for a full review). This method involves a 
four-step process by which researchers (1) assess their own beliefs about the topic prior to data collection; (2) develop new ideas during the data collection process; (3) identify tentative themes; and (4) evaluate those themes during the coding process.

Step 1 - assess own beliefs-was completed prior to the interviews began and involved the research team identifying ways in which the pandemic could be impacting community-based agencies, many of which employed practices that relied on in-person interactions. This first step was important as we too were experiencing the impact of the pandemic, and this step allowed us to initially document our preconceptions about the impact COVID-19 might have for community-based agencies and their staff and clients, and in doing so acknowledging that our experiences may influence our interpretations. Our presumptions about the impact of COVID-19 included the following: agency staff would struggle to connect and engage with clients, clients would experience a decline in services available to them, and changes in operations would require additional funding and training.

For Step 2 - develop new ideas during the data collection process - the research team periodically met to discuss, document, and reflect on the experiences participants shared. During this process, team members periodically revised, added to, or deleted themes previously identified under Step 1 after subsequent interviews. We took care to ensure that as we collected more information we differentiated between what we noted in Step 1 and what we were learning in Step 2. This included removing or redefining themes. Step 3 - identify tentative themes - the team discussed a final set of themes, which was followed by a full coding of the data in Step 4 - evaluation of themes during the coding process, including identifying any additional themes and refining those already noted.

\section{Findings}

Given the unprecedented nature of the COVID-19 pandemic and attempts of governments around the world to reduce the spread of transmission through "stay-at-home" and "shelter-at-home" orders, it is unsurprising that agency administrators discussed significant workplace changes that had a profound impact on the community-based agencies and their clients. For many agencies, this meant reconsidering and restructuring how they would maintain contact with clients and deliver services. With limited time for preparation, the community organizations had to navigate various challenges associated with the pandemic while attempting to adapt to the new social landscape. Three main themes emerged from the interviews with agency administrators: community concerns, challenges agencies faced while attempting to serve clients, and efforts to adapt and learn from this global event. Below these themes are described. The grant type-restorative justice, violence prevention, and recidivism reduction - for which the agency received funds was noted followed by a unique number assigned to individual interviews (e.g., 1, 2, 3...). 


\section{Community Concerns}

Agency administrators identified several different ways in which COVID-19 was affecting the residents in the communities they served. Some noted an increase in the number of individuals released from prisons, most of whom were entering areas with high infection rates. As one participant noted:

"Covid-19 accelerated the release of prisoners, so we've increased advocacy effort to get more people released. Once released, it's our goal for them to enter a social service program so that they're not set up for failure. . . Seems daunting given the current job market stepping out of prison, no work, high discrimination rates, unemployment. How do we support these individuals that will be successful if can't get job for 6 months year, longer" (Restorative Justice - 1).

Others noted that housing needs worsened during the pandemic. The rising number of individuals who were unemployed or laid off from work meant individuals and families struggled to maintain secure housing. In response, some individuals and families banded together and moved into single site living quarters. This meant that multiple individuals and family members were now living together, increasing the likelihood of spreading the virus between those who continued to work and those living in the home because space did not allow for social distancing or isolating those with symptoms. "COVID 19 is rising because $8 \sim 10$ people living in a house, cannot social distance. Can't isolate from those individual" (Violence Prevention-1).

Three respondents also attributed the increase in violence within the communities they served to disruption in services, two of which were agencies specifically funded for their violence prevention efforts. These respondents hypothesized that increases social isolation and the inability of agencies to serve the neediest populations exacerbated the social conditions that fostered violence. As one respondent shared,

"I don't know if this had anything to do with the rise in violence because no one was getting mental health services, no one was being checked in on. . We didn't expect COVD, so the funding is not being used in the original way we intended, but it kind of intensifies the violence because people are frustrated and they go out and do different things because they are frustrated. Stealing, selling drugs, that type of thing" (Violence Prevention -4).

\section{Agency Challenges}

Agency administrators were asked if and how the COVID-19 pandemic affected their agencies and their ability to continue program implementation. All highlighted numerous challenges their agencies faced managing this crisis, including work stoppages and interruptions to basic operations. As one administrator explained, "When in-person, there was lot more contact. Now not so much. It disrupted everything from payroll, to interactions with clients" (Violence Prevention -2). Agencies that used "open door" policies as a strategy to engage residents 
and clients and build community trust had to shutter this practice. One respondent lamented,

"We have lost the sense of community because clients, [and] volunteers are not able to enter the building. It's very sad. We closed the food pantry because one of our employees got COVID, and it was really sad. Now we don't have anyone coming into the office..." (Recidivism Reduction - 3).

Recruitment and client engagement became particularly challenging because it severed all face-to-face contacts between agency staff and community residents. Traditional methods of in-person recruitment and participation incentives, such as food, were no longer possible. Commonly used locations to recruit and engage clients, such as schools, parks, courts, and shelters, were no longer convenient recruitment and service sites. The impact was most profound for their more vulnerable clients. As one participant noted, "recruiting those most at need is more difficult because [certain] places cannot be tapped anymore. The hardest to reach are those hard to reach populations" (Recidivism Reduction -2 ).

The sudden break in face-to-face interactions forced community-based organizations to embrace online communication modalities. Many agencies, however, were not prepared for remote contact due to hardware shortages (e.g., lack of laptops and tablets) or unfamiliarity with software to facilitate remote services. As one agency administrator stated, “we've never done any of that work, google classrooms, remote orientations, [or] remote case management" (Recidivism Reduction -1). Even when they were able to secure funds for technology upgrades to maintain connections with clients, the client themselves had limited or no access to internet, smart phones, and computers or tablets. As one administrator noted, "Not everyone has food to eat, let alone a computer, so we couldn't really meet with them unless we go to them on the street because they don't have a computer to have a Zoom call or may not have a phone to have a phone call' (Violence Prevention -4).

At least three agencies, all of which were receiving funds for violence prevention programs, attempted to move activities to outdoor spaces. This solution, however, limited the number of clients programs could assist and engage. As one agency administrator of a violence prevention program shared: "We started doing community events and programming outside. Our groups have really gotten smaller. That is a reduction in youth" (Violence Prevention -6). Those who assisted clients by connecting them to services and jobs noted a decrease in what they could offer. As one individual noted, "The biggest challenge was getting people jobs" (Recidivism Reduction -1). This challenge was most often reported by agencies providing recidivism reduction programming; three administrators from agencies receiving funds to support recidivism reduction programs mentioned this challenge, as did one funded for violence prevention services. In all, most of those interviewed suggested that their programs' abilities to recruit, enroll, refer, and support clients were compromised as the result of the pandemic.

As the community-based organizations began to reopen their doors, they faced new challenges associated with the pandemic. Many agencies reporting serving clients who were living in neighborhoods with the highest infection rates. Consequently, administrators had to manage staff health concerns, some of whom became 
sick, others who were fearful because they were vulnerable to contracting COVID19 , and still others who feared infection because they did not have any or adequate health insurance despite being classified as an essential worker. As one administrator noted: "[T]he staff funded got sick and we still had to pay them even though they could not work" (Violence Prevention - 2). In some cases, administrators faced having deeply personal conversations with staff about their existing health issues, something that may not have occurred in a different environment: "[You] learn about staff health issues that you didn't know about" (Violence Prevention - 2). One agency administrator specifically shared his experience having to shut down their offices after staff tested positive for COVID-19: "[The agency] had to close the food pantry because staff had COVID. We had to shut down until [we] had results back from all the staff. Tragedy-the most basic function had to cease. We now just allow food pantry people to come in. No other staff' (Recidivism Reduction - 3). Another noted that they no longer provided food or transportation to clients as these activities were viewed as too high risk for staff and clients alike, which they felt affected the program's operations: "Work is still the same, but we can't provide food and transportation anymore. We're all virtual, so the cost for these things have shifted to technology. Recruitment is extremely difficult, as well as retention. Retention is difficult because of the lack of food and transport, but things are steady changing." (Recidivism Reduction - 5).

Administrators attempted to address staff health concerns by working to ensure their staff had access to appropriate personal protection equipment (PPE) and instituting sanitation policies and practices. These efforts, however, sometimes produced more work for staff. Services that agencies once offered, such as helping meet the transportation needs of clients by providing free rides to appointments, now meant sanitizing cars each trip taken. As one administrator noted, "It disrupted everythingpayroll, clients, enough people on the streets—some people didn't have mask on street. Sanitizing cars to transfer clients" (Violence Prevention - 2). In some instances, agencies implemented strict testing policies and practices that sometimes limited access to services. This was particularly true for programs that linked clients to temporary or emergency shelter or housing placements, as the availability of these services became more limited during the pandemic. For instance, testing procedures intended to limit the spread of COVID-19 in the shelters or temporary housing facilities sometimes meant emergency placement was sometimes unavailable, while social distancing requirements meant the agency served fewer people. These changes resulted in "more steps" because "every person that comes in and spends the night has to be tested." This administrator acknowledged that this "limits our ability to service [clients] who come in at 2am" (Recidivism Reduction -4).

Agency administrators also discussed the abrupt changes to other operational processes and practices. The shelter-in-place order made it nearly impossible, for instance, to physically secure signatures and submit hard copies of grant applications needed to secure continued funding for their programs. The lack of communication and contact with clients also meant that programmatic goals and outcomes were not always achieved. The failure to document measurable outcomes created uncertainty around an agency's ability to prove its efforts were worth funding. As one agency administrator, "Where does that leave us for future funding and credibility 
when we say we don't have data [or] other participant engagement?" (Restorative Justice-1). This also meant the pandemic limited the ability for community basedorganizations to self-evaluate and determine areas of improvement.

\section{Agency Adaptation and Learning}

A clear theme that emerged in the interviews was the various ways in which community-based agencies adapted to their changing work environments. All of the agencies experienced work stoppage as the result of the pandemic, and many of individuals interviewed reported believing the shelter-at-home order would be temporary. They soon learned otherwise and quickly tried to adapt to the new environment. The most common strategy employed, something all but one agency mentioned, was shifting activities to online platforms, and more specifically to hosting events through video conferencing software. This meant securing software that would enable video conferencing, computer equipment for their staff, and tablets for their clients. Some were able to secure additional funding through donors to offset the costs associated with moving their work remotely. Others absorbed these additional costs or made due with existing resources. As one agency noted, "In our communities, we lack internet and computers. Even if we wanted to meet with our youth, they do not have internet and computers. We had to realign our budget and buy tablets" (Violence Prevention -6). A few mentioned creating videos that were posted online for clients to view, although this was much less common than video conferencing.

The shift to remote services affected everything from providing staff and community trainings, conducting staff meetings, engaging and serving clients, building community trust, and maintaining effective case management practices. In many instances, staff were able to recreate similar programmatic activities using video conferencing technology. As one administrator shared: "[We] had to create google classrooms and develop class management. [We] could not enroll participants in the first months." The shift to remote offerings meant, however, that agency administrators and staff had to learn how to use new software and adapt their existing practices to being remote. This took away staff time that previously was devoted to engaging and serving clients pre-pandemic. One agency reported that staff had already been working on plans for how to conduct case management and manage privacy and confidentiality concerns in online settings prior to the pandemic. That administrator shared, "[We] were already doing zoom mediation and had plans in place for case management, privacy, confidentiality in place" (Restorative Justice - 2). The pandemic simply accelerated these plans.

A few agency administrators restarted in-person activities when the weather permitted to outdoor spaces, which was deemed safer than indoors. These outdoor activities were deemed necessary given the limited access their clients had to the internet and computers. However, it also meant significantly reducing the number of clients who could participate. As one agency staff person noted "Our groups have really gotten smaller. That is a reeducation in youth [served]" 
(Violence Prevention - 6). Those interviewed also talked about the importance of reassessing the needs of their communities and clients during the pandemic so that they could realign their services to meet these new demands. This included seeing a larger number of individuals who now sought services. As one staff person noted, there was an "increase in participants coming in along with the whole family. For counseling, for different needs... We didn't expect COVID, but did serve those needs" (Violence Prevention - 4). A few agency staff reported developing new activities to specifically address pandemic-related stress, such as "creating peace rooms for students to unpack what occurred" (Restorative Justice - 1).

Many of those interviewed also noted that their agency staff handed out personal protection equipment and hand sanitizer and shared information with residents about the dangers of COVID-19 and the precautionary steps they can take to prevent infection or spread of the virus. One interviewee noted that their staff "morphed into an extension of public health" (Violence Prevention - 4), as they attempted to address "false narrative[s]" about COVID-19, hand out masks and sanitizers, and prevent looting that occurred following civil unrest. These activities oftentimes fell outside of their grant-funded work, forcing some agencies to try to identify private funds to fill their budget gaps. Others attempted to address this by forging new partnerships with other communitybased agencies in an attempt to piece together the services their clients needed. The most frequently cited partnership was with the local food depositories to help clients who were "not coming in because of fear...people [were] starving on the westside [of the city]" (Violence Prevention - 5) by offering door-todoor food service.

Although the pandemic affected operations, most agency administrators shared ways in which their agencies benefited from this new shift. Some indicated that the lessons they learned about what could be performed remotely would advantage their clients in the long-term. One administrator shared that the pandemic taught his agency that,

"we don't need to do in-person interviews all the time. We can do case management where an individual doesn't need to leave the house. When they can't make it, they say it's because 'I didn't have a babysitter, I didn't have transportation.' It actually improved our work, it allows people to attend meetings more often, and to be frank, I think we are doing a better job now" (Recidivism Reduction - 1).

Two administrators noted that greater awareness of the impact of COVID-19 on vulnerable populations meant additional funding to support housing, food, and other needs of their clients was now available. This presented an infusion of additional cash for these agencies, and consequently, their clients. One administrator shared the following, "Financially, it has impacted us in amazing way... I think funding opportunities will come our way because of the pandemic" (Recidivism Reduction - 3). 


\section{Discussion}

The COVID-19 pandemic forced both state and community agencies to reevaluate operations. In attempt to reduce the spread of COVID-19, law enforcement agencies reassigned personnel to daily patrol (Winton \& Tcheckmedyian, 2020), divided staff to minimize exposure (PERF, 2020), attempt to handle non-emergency and nonviolent calls via telephone (NPF, 2020), implemented cite-and-release programs for misdemeanor crimes, cancelled or modified community-oriented policing and outreach initiatives to reduce the close proximity between officers and members of the public (NPF, 2020), and transitioned personnel to working remotely (Bates, 2020; NPF 2020). As a result of COVID-19, the courts could not conduct trials and had to reconsider pre-trial custody and disincentivize custodial sanctions (Skolnik, 2020). In jurisdictions like Los Angeles County, the fewer number of trial convictions coupled with a reduction in arrests decreased the number of individuals in correctional facilities (Poston, 2020; Winton \& Tcheckmedyian, 2020). Correctional facilities also implemented policies to reduce the spread of infection such as suspending facility transfers, limiting attorney contacts, and utilizing video conferencing for personal visits, legal meetings, and telemedicine (Miller \& Blumstein, 2020).

Similarly, our data reveal that COVID-19 pandemic forced non-profit, communitybased agencies to change dramatically their day-to-day operations. The interviews conducted for this study occurred early in the pandemic (July - September 2020) and offered a unique opportunity to understand its effect on programs that aim to reduce violence and offending. Our analytical strategy began by acknowledging our preconceived ideas about the impact of COVID-19 on agency operations based on our experiences trying to navigate the pandemic. We accomplished this by discussing and documenting themes we thought might emerge. These included the belief that agency staff would struggle to connect and engage with clients, clients would experience a decline in services available to them, and changes in operations would require additional funding and training. By documenting these preconceived notions, we were able to appreciate more fully if and how the data truly reflected these issues. In some cases, the data were confirmatory. For instance, we were correct that agencies experience challenges engaging clients and providing the same level or, in some cases, types of services. (e.g., agency engagement issues, service availability changes).

We did not consider, however, how quickly agencies were able to adapt their new work environments and the ways in which agencies problem solved and innovated. Moreover, agency administrators shared various ways they stepped into new roles for the benefit of the community, including those that promoted health safety and well-being. Although some agencies reported receiving additional funding to support these efforts as monies became available through local government agencies (e.g., dollars for personal protection equipment), many also completed these tasks out of concern for the communities they served even at the potential expense of their personal health and well-being. These efforts illustrate the ways in which community-based agencies work to address localized problems. Not only did these agencies work to ensure residents had access to personal 
protection equipment, such as hand sanitizer and masks, but some agencies also engaged actively in addressing misinformation and myths surrounding who was at-risk of contracting COVID-19. Many of the agency administrators interviewed devoted time and energy to handing out PPE, hand sanitizer, and sharing information with residents about the dangers of COVID-19 and precautionary steps they could take to prevent infection or spread of the virus. Thus, these agencies became integral to information sharing during the pandemic, often filling the gap produced by a breakdown in infrastructure, equipment and technology inefficiencies, and problems with the content and flow of information (Pan et al., 2020). These agencies felt such work was important because the neighborhoods they served were experiencing higher rates of infection compared to other areas of the county or state and because not all residents understood the risk. These agencies represented a network of resources that could quickly mobilize for the benefit of communities in response to a sifting environment, underscoring the importance of community-based agencies in promoting community resiliency. Some also created spaces for young people to express how the pandemic was affecting their lives. When viewed together, these activities are consistent with what Sharkey (2018) refers to as a "community quarterback," or agencies who "oversee public spaces, to take care of everyone within them, and to make sure the neighborhood does not begin to fall apart" (p. 167).

Through a framework of community resilience, agencies adapted to changing circumstances and challenges (Holling, 1973; Patel et al., 2017) presented by COVID-19 for the benefit of their clients and the community at large. Community social capital is important because local community groups can identify vulnerabilities, priorities, and appropriate solutions that are more relevant and feasible than federal and state governments (Monteil et al., 2020; Nakagawa \& Shaw, 2004; Zahnow et al., 2019). Community-based organizations drew on their human, economic, and social capital to work collectively and address their client's needs. Administrators mobilized networks, norms, and trust to facilitate action and cooperation for mutual benefit (Putnam, 1993). As federal and state governments closed their doors, communities relied on the concept of social cohesion, the degree of social connectedness and solidarity between different community groups, as well as the level of trust and connectedness between individuals and across community groups (Ludin et al., 2019; Townshend et al., 2015). Communitybased agencies helped facilitate this social cohesion. The pandemic forced community-based agencies to reactivate their assets to advocate on behalf of their clients. Building on the concept of social capital, community-based organizations strengthened a sense of community, commitment to place, shared information and facilitated trust during a crisis (Aldrich, 2012).

The interviews highlighted numerous challenges agencies faced as they provided violence prevention and reentry support services. All of the agencies experienced temporary work stoppages, and even after operations restarted, programs reported significant changes to how their organizations recruited and engaged clients. Most organizations responded to the stay-at-home orders by moving their activities to online platforms and remote options or offering smaller sized outdoor activities. Shifts to remote work meant administrators revised budgets account for 
unexpected costs associated with working remotely. Some program administrators were able to secure additional funding to offset these costs.

Despite their efforts to restructure their programs, many acknowledged difficulties recruiting, enrolling, supporting, and referring clients. Clients who lacked social supports or resources were impacted the most, further highlighting the inequities of the pandemic experienced by those most vulnerable. Despite high level of social capital in marginalized communities, individuals are less likely to have access to opportunities and resources for social and economic recovery from pandemics (Pitas \& Ehmer, 2020). According to Boserup et al. (2020), social isolation associated with quarantine and shelter-in place-orders heightened economic and health vulnerabilities for marginalized populations like IPV victims because of a lack of social support systems. This finding is consistent with that noted elsewhere; the social determinants that make individuals and communities susceptible to other negative outcomes, including poor health, criminal justice involvement, mass incarceration, housing and food insecurity, intensified the impact of the pandemic (Rosenberg et al., 2020; Zheng \& Walsham, 2021). For particularly vulnerable populations like IPV victims, the shelter-in-place orders and social distancing guidelines restricted individuals to their place of residency with limited access to social service providers (Mazza et al., 2020). During the early days of the pandemic, the economic uncertainty and record levels of unemployment intensified levels of stress and increased the risk of marital conflict and violence (Kaukinen, 2020).

Some of the difficulties agency staff experienced assisting clients was due to their clients having limited or no access to internet, smart phones, and computers or tablets. Differential access to computer technology and the Internet has been the subject of numerous studies, many of which show that poor or racial and ethnic minorities are less likely to have reliable access to the digital resources needed as compared to their wealthier and White counterparts (Chakraborty \& Bosman, 2005). Disparities in access to the Internet is often associated with information inequality (Yu, 2006). The pandemic further highlighted the consequences of the digital divide beyond simply information acquisition; limited or no access to technology meant that individuals could not connect to social support systems and services. Prosocial support services have been used historically as an evidence-based strategy to assist individuals at greatest risk for becoming justiceinvolved or continued justice system involvement (Duwe \& Johnson, 2016). Yet, most of these services are heavily reliant on face-to-face engagement practices that were either not feasible or difficult to sustain at pre-pandemic levels. Other research similarly found that community organizations faced challenges disrupting the cycle of violence in working class communities during the pandemic due to significant changes in what violence interrupters could do. Specifically, early engagement activities, such as showing up to the hospital soon after a shooting in an effort to support victims and their loved ones and mediate potential conflict resulting from the shooting, for instance, were no longer possible because of strict hospital visitation policies aimed at reducing the spread of COVID-19 (Altheimer et al., 2020). 


\section{Conclusion}

The COVID-19 pandemic profoundly shaped crime, criminal justice operations, and community organizations' abilities to serve their clients. Although governmental agencies worked to mitigate the spread of COVID-19 by modifying practices, some research suggests that shelter in place orders and quarantine guidelines may have heighted the risk of victimization by increasing financial stress and limiting social services. This study supports the notion that a national COVID-19 research program is needed to critically understand the impact of the pandemic on crime and response and shape effective policy. As posited by Miller and Blumstein (2020), a conceptual framework can direct the tone of inquiry, issues researched, and related attributed significance. Such a framework is a purposeful activity that can produce a greater understanding of how large-scale events affect neighborhoods and the agencies that work within them.

Our study suggests that efforts to understand the pandemic's impact on criminal justice agencies and communities must also include research that examines the effects of the pandemic on local non-profit organizations charged with supporting crime reduction activities in communities. Several researchers have highlighted the importance of community-based agencies in supporting crime reduction strategies within neighborhoods across the US (see, for instance, Sharkey, 2018). Yet, analysis of crime and large-scale events sometimes overlook localized efforts undertaken by non-governmental entities. Our study addresses this limitation by documenting the experiences of community-based agency administrators as they managed changes to their work environments during the early spring and summer months of COVID-19 while trying to maintain violence prevention and support services for their clients, most of whom also lived in communities experiencing high rates of violent crime, mass incarceration, and COVID-19 infection rates. Our findings suggest that community-based organizations quickly adapted to the new social landscape by executing social distancing and remote contact measures. Despite fears of contamination, agency staff members continued to serve the most vulnerable populations during the pandemic.

When viewed through a community resiliency framework, the efforts completed by agency administrators and their staff highlight how quickly community-based agencies could be activated within vulnerable communities to serve those at-risk or in need of support. This study also exposed the social disparities related to technology access and health in working class communities of color. We conclude that any national research program that seeks to understand how the pandemic affected crime also consider social service providers as another variable explaining the complexities of COVID-19.

It is important to note that this study's findings are based on a small, nonrepresentative sample size of agency administrators during the early months of the pandemic. Additional research should determine the generalizability of the findings presented here and to cull further the lessons learned during this unprecedented event, and more specifically, to identify ways in which government and private funding agencies can support efforts that will improve community-based responses to vulnerable population during crises. 


\section{Appendix A. Interview Protocol}

\section{Organization and Community Background}

1. The [agency] staff have provided us with information about agencies that have been funded or applied for [agency] funds. Those materials were very helpful for learning about your agency. However, we would love to hear from you about your organization. Can you briefly describe what your agency does?

2. How long have you been working in the communities you serve?

3. Do you feel the demographic of your staff accurately reflects the population you serve? If not, do you feel that this could be a barrier in building rapport/connections with said population?

4. How is your agency funded? If multiple sources: How do you manage multiple funding sources?

2. What do you feel are some of the challenges and strengths of the communities you serve as it relates the community to be a safe and peaceful place to live and work?

3. What areas do you feel would help the communities you serve address the challenges identified? Of these areas, which do you feel are adequately funded to address these challenges?

4. As you know, [agency] funding focuses on three areas: Recidivism Reduction, Violence Prevention, and Restorative Justice. Given your community's needs, in what ways does this funding opportunity meet the needs of your community?

- What might you suggest the [agency] consider adding as programs or activities that could be funded? Why do you feel these programs and activities are important?

\section{Grant Application Decision making}

5. We thought it might be nice to start by having you describe the program that you are sought funding from the [agency]

- How did this project come about?

- Was it a new initiative developed specifically for this grant application, or was the initiative something your agency already worked on?

- Who was involved in deciding what project to propose?

6. What made you decide to apply for funding available through the [agency]? 
- How did you decide to apply for (Restorative Justice/Recidivism Reduction/ Violence Prevention) grant? Who was involved, what factors were taken into consideration?

7. Do you consider the funding amount sufficient to support the program you proposed? Why or why not?

- Were there activities that you wanted to include in the grant application that were not allowable?

- Were there activities that you wanted to include but couldn't due to lack of available funds, although they were allowable? If yes, please share?

8. Did you attend the pre-bidders presentation in [month]? Can you share with us what aspects of that presentation were helpful?

- What was missing that you wished would have been addressed?

- How responsive do you feel were [agency] staff to your questions?

9. We know that programs expend a lot of effort in developing their grant applications. It takes time and staff resources to do them. What is the process you use to develop the grant application?

- Who was involved?

- If you were unable to hire a grant writer, do you feel you had the resources available to fully understand the requirements of this application?

- How much time did it take to complete? Did you feel there enough time to complete it? If no, what timeline would have been more helpful?

10. What parts of the application do you feel were most challenging to complete? Why?

11. If you were able to change the grant application process, what changes would you suggest?

- Why are those changes important? What do you hope they might accomplish?

- If your request for funding was denied, do you feel you were given appropriate clarity/feedback as to why this was? Do you feel that eligibility requirements 
were clearly explained during the application process? Was there staff available to address criteria that felt unclear?

- If your agency has multiple grants, do you feel that managing these grants and contracts pose high overhead costs? How does your agency handle the increased reporting and oversight responsibilities grants bring?

12. How did the recent COVID-19 pandemic impact your ability to complete the grant application?

- How as working remotely impacted your agency's ability to do community outreach?

\section{Implementation (for previously funded organizations)}

13. According to our files, you have a project that is currently funded through [agency]. We are interested in learning about the challenges and successes your organization has experienced while carrying out that work and the support received from the [agency] staff. Although we have some information about your program based on the files the [agency] staff have provided us, we would like you to describe in detail the program that is currently funded by [agency].

14. What other funds are being used to support that program?

15. How adequate would you de describe the funds available to support the program?

16. What unforeseen costs has your organization incurred related to this project?

17. For this program, how would you define success? In other words, how would know that you have achieved the results you are hoping for?

18. What achievements have you secured through your program?

19. What challenges have you experienced? How have you attempted to address these changes and have those attempts been successful?

20. How were the communities being serviced involved in decision-making for newly implemented projects or events/programs?

21. How have the [agency] staff supported your agency during the implementation of your program?

22. What might you suggest are things that could be done by the [agency] staff to better support implementation activities of grantees?

19. What were things you learned during implementation that may be helpful for other grantees to know about in advance?

20. What funding requirements - reports, data collection, etc.—-do you find difficult to maintain?

21. How does your agency use these data? 
22. According to the [agency] grant materials, programs must collect and share data about the clients they serve. How do community members feel about the sharing of an individual's personal information (Name/DOB/Gender/Race) for evaluation purposes?

23. How as COVID-19 impacted your ability to implement your program as designed?

- What did you have to change/modify?

- How do you feel this has impacted your clientele/community?

\section{Program Sustainability}

23. Now we would like to talk a bit about the long-term vision you have for the program you currently have funded (or if not funded, the program you proposed). How would you describe your agency's current capacity to support this program if funding through the [agency] were not available?

24. According to the [agency] grant materials, programs can receive funding from up to three grant cycles. How do you feel that will impact your agency's ability to maintain the program as currently proposed/operating?

25. What other sources of funding might you be able to obtain?

26. What might be helpful for you as you being planning for finding an alternative funding source?

27. Given your experience seeking funding, what recommendations would you provide to [agency] staff specifically or funders more generally about funding practices they use?

- Length of funding

- Types of activities that can be funded

- Amount allowed for administrative expenses

- Others?

28. We appreciate your willingness to participate in an interview. Before we hang up, do you have any additional you would like to add? Anything you feel we did not cover? Any questions for us?

Authors' Contributions All authors contributed to the study conception and design. Material preparation, data collection and analysis were performed by Dr. Megan Alderden and Dr. Xavier Perez. The first draft of the manuscript was written by Drs. Alderden and Perez and all authors commented on previous versions of the manuscript. All authors read and approved the final manuscript.

Funding The data used for this article was collected as part of a larger evaluation project funded by the Cook County Justice Advisory Council, Grant Agreement No. 1953-18004. 
Data Availability (data transparency).

Code Availability (software application or custom code).

\section{Declarations}

Consent to Participate Informed consent was obtained from all individual participants included in the study.

Consent for Publication No identifying information about participants is shared.

Ethics Approval The methodology for this study was approved by the Institutional Review Board of DePaul University.

Conflicts of Interest The authors have no conflicts of interest to declare that are relevant to the content of this article.

\section{References}

Adhikari, S., Pantaleo, N. P., Feldman, J. M., Ogedegbe, O., Thorpe, L., \& Troxel, A. B. (2020). Assessment of community-level disparities in coronavirus disease 2019 (COVID-19) infections and deaths in large US metropolitan areas. Journal of the American Medical Association Network Open, 3(7), e2016938-e2016938. https://doi.org/10.1001/jamanetworkopen.2020.16938

Aldrich, D. P. (2012). Building resilience: Social capital in post-disaster recovery. University of Chicago Press.

Altheimer, I., Duda-Banwar, J., \& Schreck, C. J. (2020). The impact of CoViD-19 on community-based violence interventions. American Journal of Criminal Justice, 45(4), 810-819. https://doi.org/10. 1007/s12103-020-09547-z

Ashby, M. P. J. (2020). Initial evidence on the relationship between the coronavirus pandemic and crime in the United States. Crime Science, 9(6), 1-16.

Bates, J. (2020, April 2). Police departments, sheriffs' offices across the U.S. grapple with COVID-19's impact on public safety-And their own. TIME. https://time.com/5812833/coronavirus-policedepartments/

Boman, J. H., \& Gallupe, O. (2020). Has COVID-19 Changed Crime? Crime Rates in the United States during the Pandemic. American Journal of Criminal Justice, 45, 537-545.

Boserup, B., McKenney, M., \& Elkbuli, A. (2020). Alarming trends in US domestic violence during the COVID-19 pandemic. The American Journal of Emergency Medicine. https://doi.org/10.1016/j. ajem.2020.04.077

Brinkley-Rubinstein, L., \& Cloud, D. H. (2020). Mass incarceration as a social-structural driver of health inequities: A supplement to AJPH. American Journal of Public Health, 110(Suppl 1), S14.

Burki, T. (2021). COVID-19 among American Indians and Alaska Natives. The Lancet Infectious Diseases, 21(3), 325-326. https://doi.org/10.1016/S1473-3099(21)00083-9

Campedelli, G. M., Aziani, A., \& Favarin, S. (2020). Exploring the Effects of COVID-19 Containment Policies on Crime: An Empirical Analysis of the Short-term Aftermath in Los Angeles. American Journal of Criminal Justice, 46, 704-727.

Carson, E. A. (2020). Prisoners in 2019 (NCJ Publication No.: 255115). Washington DC: U.S. Department of Justice, Office of Justice Programs, Bureau of Justice Statistics.

Chakraborty, J., \& Bosman, M. M. (2005). Measuring the digital divide in the United States: Race, income, and personal computer ownership. The Professional Geographer, 57(3), 395-410. https:// doi.org/10.1111/j.0033-0124.2005.00486.X

Duong, V., Luo, J., Pham, P., Yang, T., \& Wang, Y. (2020). The ivory tower lost: How college students respond differently than the general public to the covid-19 pandemic. In 2020 IEEE/ACM International Conference on Advances in Social Networks Analysis and Mining (ASONAM) (pp. 126130). https://doi.org/10.1109/ASONAM49781.2020.9381379 
Duwe, G., \& Johnson, B. R. (2016). The effects of prison visits from community volunteers on offender recidivism. The Prison Journal, 96(2), 279-303. https://doi.org/10.1177/0032885515618468

Ford, T., Reber, S., \& Reeves, R. V. (2020). Race gaps in COVID-19 deaths are even bigger than they appear. The Brookings Institution: Washington, DC, USA.

Franco-Paredes, C., Ghandnoosh, N., Latif, H., Krsak, M., Henao-Martinez, A. F., Robins, M., Barahona, L. V., \& Poeschla, E. M. (2020). Decarceration and community re-entry in the COVID-19 era. The Lancet Infectious Diseases, 21, e10-15. https://doi.org/10.1016/S1473-3099(20)30730-1

Hawks, L., Woolhandler, S., \& McCormick, D. (2020). COVID-19 in prisons and jails in the United States. JAMA Internal Medicine, 180(8), 1041-1042. https://doi.org/10.1001/jamainternmed.2020. 1856

Holling, C. S. (1973). Resilience and stability of ecological systems. Annual Review of Ecology and Systematics, 4(1), 1-23. https://doi.org/10.1146/annurev.es.04.110173.000245

Iguchi, M. Y., London, J. A., Forge, N. G., Hickman, L., Fain, T., \& Riehman, K. (2002). Elements of well-being affected by criminalizing the drug user. Public Health Reports, 117(Suppl 1), S146.

Jackman, T. (2020). Amid pandemic, crime dropped in many U.S. cities, but not all. Washington Post. https:// www.washingtonpost.com/crime-law/2020/05/19/amid-pandemic-crimedropped-many-us-cities-not-all/

Kaukinen, C. (2020). When Stay-at-Home Orders Leave Victims Unsafe at Home: Exploring the Risk and Consequences of Intimate Partner Violence during the COVID-19 Pandemic. American Journal of Criminal Justice, 45, 668-679.

Kawachi, I., \& Berkman, L. (2000). Social cohesion, social capital, and health. In L. F. Berkman, I. Kawachi, \& M. M. Glymour (Eds.), Social Epidemiology (pp. 174-190). Oxford University Press.

Kruger, D. J., \& De Loney, E. H. (2009). The association of incarceration with community health and racial health disparities. Progress in Community Health Partnerships: Research, Education, and Action, 3(2), 113-121. https://doi.org/10.1353/cpr.0.0066

Kulkarni, S. P., Baldwin, S., Lightstone, A. S., Gelberg, L., \& Diamant, A. L. (2010). Is incarceration a contributor to health disparities? Access to care of formerly incarcerated adults. Journal of Community Health, 35(3), 268-274. https://doi.org/10.1007/s10900-010-9234-9

Ludin, S. M., Rohaizat, M., \& Arbon, P. (2019). The association between social cohesion and community disaster resilience: A cross-sectional study. Health \& Social Care in the Community, 27(3), 621-631. https://doi.org/10.1111/hsc.12674

Mazza, M., Marano, G., Lai, C., Janiri, L., \& Sani, G. (2020). Danger in Danger: Interpersonal Violence During COVID-19 Quarantine. Psychiatry Research, 289

Mercy, J. A., Rosenberg, M. L., Powell, K. E., Broome, C. V., \& Roper, W. L. (1993). Public health policy for preventing violence. Health Affairs, 12(4), 7-29. https://doi.org/10.1377/hlthaff.12.4.7

Miller, J. M., \& Blumstein, A. (2020). Crime, Justice \& the COVID-19 Pandemic: Toward a National Research Agenda. American Journal of Criminal Justice, 45, 515-524.

Monteil, C., Simmons, P., \& Hicks, A. (2020). Post-disaster recovery and sociocultural change: Rethinking social capital development for the new social fabric. International Journal of Disaster Risk Reduction, 42, 101356. https://doi.org/10.1016/j.ijdrr.2019.101356

Morgan, D.L., Nica, A. (2020). Alterative thematic inquiry: A new method for analyzing qualitative data. International Journal of Qualitative Methods, 19 https://doi.org/10.1177/F1609406920955118

National Police Foundation (NPF). (2020). COVID-19 Resources for Law Enforcement. https://www. policefoundation.org/covid-19/

Nakagawa, Y., \& Shaw, R. (2004). Social capital: A missing link to disaster recovery. International Journal of Mass Emergencies and Disasters, 22(1), 5-34.

Norris, F. H., Stevens, S. P., Pfefferbaum, B., Wyche, K. F., \& Pfefferbaum, R. L. (2008). Community resilience as a metaphor, theory, set of capacities, and strategy for disaster readiness. American Journal of Community Psychology, 41(1), 127-150. https://doi.org/10.1007/s10464-007-9156-6

Pan, S. L., Cui, M., \& Qian, J. (2020). Information resource orchestration during the COVID-19 pandemic: A study of community lockdowns in China. International Journal of Information Management, 54, 102143. https://doi.org/10.1016/j.ijinfomgt.2020.102143

Patel, S. S., Rogers, M. B., Amlôt, R., \& Rubin, G. J. (2017). What do we mean by 'community resilience'? A systematic literature review of how it is defined in the literature. PLoS Currents, 9. https:// doi.org/10.1371/currents.dis.db775aff25efc5ac4f0660ad9c9f7db2

Payne, J., \& Morgan, A. (2020). Property Crime during the COVID-19 Pandemic: A comparison of recorded offence rates and dynamic forecasts (ARIMA) for March 2020 in Queensland, Australia.

Pfefferbaum, R. L., \& Klomp, R. W. (2013). Community resilience, disasters, and the public's health. Community Engagement, Organization, and Development for Public Health Practice, 275-298. 
Pitas, N., \& Ehmer, C. (2020). Social Capital in the Response to COVID-19. American Journal of Health Promotion, 34(8), 942-944. https://doi.org/10.1177/0890117120924531

Podewils, L. J., Burket, T. L., Mettenbrink, C., Steiner, A., Seidel, A., Scott, K., Cervantes, L., \& HasnainWynia, R. (2020). Disproportionate incidence of COVID-19 infection, hospitalizations, and deaths among persons identifying as Hispanic or Latino-Denver, Colorado March-October 2020. Morbidity and Mortality Weekly Report, 69(48), 1812. https://doi.org/10.15585/mmwr.mm6948a3

Philadelphia Police. (2020). Crime maps \& stats: Homicide. https:/www.phillypolice.com/crime-maps-stats/

Pietrawska, B., Aurand, S. K. \& Palmer, W. (2020). Covid-19 and crime: CAP's perspective on crime and loss in the age of Covid-19: Crime in Los Angeles and Chicago during Covid-19. CAP Index, 19(3).

Poston, B. (2020). Arrests by LAPD and Sheriff's Department drop amid coronavirus outbreak. Los Angeles Times. https://www.latimes.com/california/story/2020-03-18/lapd-arrests-crime-coronavirus

Police Executive Research Forum. (2020). Responding to the COVID-19 Coronavirus. https://www. policeforum.org/coronavirus

Putnam, R. (1993). The prosperous community: Social capital and public life. The American Prospect, 13(4).

Reinhart, E., \& Chen, D. L. (2020). Incarceration and its disseminations: COVID-19 pandemic lessons from Chicago's Cook County Jail: Study examines how arrest and pre-trial detention practices may be contributing to the spread of COVID-19. Health Affairs, 39(8), 1412-1418. https://doi.org/10. 1377/hlthaff.2020.00652

Rosenberg, A., Keene, D. E., Schlesinger, P., Groves, A. K., \& Blankenship, K. M. (2020). COVID19 and Hidden Housing Vulnerabilities: Implications for Health Equity, New Haven, Connecticut. AIDS and Behavior, 24, 2007-2008. https://doi.org/10.1007/s10461-020-02921-2

Rosenfeld, R., \& Lopez, E. (2020). Pandemic, social unrest, and crime in US Cities. Washington, DC: Council on Criminal Justice. Retrieved from: https://www.novahtrp.com/uploads/1/2/5/9/125988329/ pandemic_social_unrest_and_crime_in_u.s._cities.pdf

Saloner, B., Parish, K., Ward, J. A., DiLaura, G., \& Dolovich, S. (2020). COVID-19 cases and deaths in federal and state prisons. Journal of the American Medical Association, 324(6), 602-603. https:// doi.org/10.1001/jama.2020.12528

Sharkey, P. (2018). Uneasy Peace. W.W. Norton \& Company: New York, New York.

Shayegh, S., \& Malpede, M. (2020). Staying Home Saves Lives, Really! In Staying home saves lives, really! RFF-CMCC European Institute on Economics and the Environment. https://doi.org/10.2139/ ssrn.3567394

Sherry, S. (2021). More than 1,000 Illinois prisoners to be released under COVID-19 lawsuit settlement. Chicago Sun-times. Retrieved from: https:/chicago.suntimes.com/coronavirus/2021/3/23/22346690/ prisoner-release-covid-19-settlement-coronavirus-illinois-department-corrections

Singal, J. (2021). America saw a historic rise in murders in 2020. Why? New York Intelligencer. Retrieved from: https://nymag.com/intelligencer/2021/02/america-saw-a-historic-rise-in-murders-in-2020why.html

Stickle, B., \& Felson, M. (2020). Crime Rates in a Pandemic: The Largest Criminological Experiment in History. Southern Criminal Justice Association, 45, 525-536.

Skolnik, T. (2020). Criminal law during (and after) COVID-19. Manitoba Law Journal, 43(4), 146-180.

Townshend, I., Awosoga, O., Kulig, J., \& Fan, H. (2015). Social cohesion and resilience across communities that have experienced a disaster. Natural Hazards, 76(2), 913-938. https://doi.org/10.1007/ s11069-014-1526-4

Vivolo, A. M., Matjasko, J. L., \& Massetti, G. M. (2011). Mobilizing communities and building capacity for youth violence prevention: The national academic centers of excellence for youth violence prevention. American Journal of Community Psychology, 48(1), 141-145. https://doi.org/10.1007/ s10464-010-9419-5

Waldrop, T. (2020). Coronavirus has police everywhere scrambling to respond as their forces are reduced. https://www.cnn.com/2020/04/01/us/police-coronavirus/index.html

Winton, R., \& Tcheckmedyian, A. (2020). Coronavirus has authorities putting more police on streets, releasing inmates from jails. Los Angeles Times. https://www.latimes.com/california/story/20200317/coronavirus-has-authorities-putting-more-police-on-streets-releasing-inmates-from-jails.

World Health Organization. (2021). The next flu pandemic: A matter of 'when', not 'if'. Retrieved from: http://www.emro.who.int/pandemic-epidemic-diseases/news/the-next-flu-pandemic-a-matter-ofwhen-not-if.html.

Yu, L. (2006). Understanding information inequality: Making sense of the literature of the information and digital divides. Journal of Librarianship and Information Science, 38(4), 229-252. https://doi. org/10.1177/0961000606070600 
Zahnow, R., Wickes, R., Taylor, M., \& Corcoran, J. (2019). Community social capital and individual functioning in the post-disaster context. Disasters, 43(2), 261-288. https://doi.org/10.1111/disa. 12317

Zeng, Z., \& Minton, T. D. (2021). Jail inmates in 2019 (NCJ Publication No.: 255608). Washington DC: U.S. Department of Justice, Office of Justice Programs, Bureau of Justice Statistics.

Zheng, Y., \& Walsham, G. (2021). Inequality of what? An intersectional approach to digital inequality under Covid-19. Information and Organization, 31(1), 100341. https://doi.org/10.1016/j.infoandorg. 2021.100341

Publisher's Note Springer Nature remains neutral with regard to jurisdictional claims in published maps and institutional affiliations. 